\title{
HACCP Implementation in Fisheries Industry: Experiences of Thailand
}

\author{
SIRILAK SUWANRANGSI \\ Chief, Fish Inspection Center (Bangkok) Fish Inspection and Quality Control Division \\ Department of Fisheries, Kasetklang, Chattuchak, Bangkok 10900. Thailand. \\ Tel.6625580153,Fax.6625580136E mail: sirilak_s@yahoo.com
}

SUMMARY: This article is based on the experience of the Thai Department of Fisheries in working with the fishery industry in Thailand and experiences shared among developing countries from various workshops, seminars and regional meetings on HACCP implementation. It shows some of the main problems encountered in implementing HACCP successfully, and how the industry and government have sought to overcome them. The Department of Fisheries (DOF), Thailand implemented HACCP based fish inspection programs in 1991. The program involves HACCP implementation by the industry exporting fishery products, reviewing inspection procedures, training for inspectors and industry and regulatory audit. Since 1996, HACCP based quality systems have been required for the export -oriented fish processing sector. The implementation of HACCP is making headway in food safety management systems of fishery industry in Thailand, through tremendous commitment of both the industry and government, in the face of challenges and problems. Successful implementation to date required a common understanding of standard and procedures as well as the competence of personnel involved.

KEYWORDS: HACCP, document, implementation, food safety, hygiene, requirements, fisheries, Thailand

\section{INTRODUCTION}

The importance of HACCP systems to the fishery industry in developing countries such as Thailand reflects the increasing importance of the international trade in fresh fish and fish products. Fish, shellfish and fishery products are widely traded, with no less than 195 countries having exported part of their production and some 180 countries having reported fishery imports of varying amounts in 1996. The international trade in fish now represents $37 \%$ of total world fish production

The Thai fisheries industry has enjoyed substantial export growth for more than a decade. Exports consisting primarily of canned tuna, other canned seafood and frozen shrimp, increased from 2.3 billion US $\$$ in 1990 to 5 billion US\$ in 1997 , before falling to 4.1 billion US\$ in 1999 as a result of the economic crisis in Asia and increasing price competitiveness in the fisheries market. Japan was the main importer of Thai fishery products until the end of 1997. In 1998, USA became the largest importer, accounting for $31 \%$ of total production. Other major importers are the European Union (EU), Australia, Canada and other Asian countries. China has emerged as a significant importing country in the past few years, with significant potential for the future.
The use of HACCP systems in the fishery industry is now on a global scale. Since it first emerged, the concept has increased in importance, partly through its endorsement by Codex Alimentarius, and particularly with the endorsement of HACCP systems to control imported fish and fishery products by the EU and USA, two of the most important fish importers. Currently over forty countries have announced HACCP initiatives for the control of fish production, processing and distribution.

\section{HACCP Implementation in Thai Fisheries Industry}

The Department of Fisheries(DOF) is a main organization providing services to the export industry on fish inspection and quality assurance. Importing countries worldwide recognizes the fish inspection service of the Department especially the EU, Canada, Australia, New Zealand, USA, Japan etc. Since 1960s, the fish inspection and quality control services of the has been engaged mostly in pre shipment inspection and facilities inspection, which is theprinciple means used by most govemmental agencies in the world to control safety of food. The DOF inspects exported fishery products for compliance with intemational 
standards and where applicable, the importers requirements related to health, safety quality, identity, process and handling. The fact that Thailand is one of the major exporters of fishery products, exporting to major market like Japan, North American and European and other markets e.g. middleeast, Australia, New Zealand and SouthAmericancountries, with approximately 200 registered operations producing nearly 800,000 tones of export products annually, combined with the fact that personnel directly responsible for inspection and quality control at the Fish Inspection and Quality Control Division of DOF has a total person year compliment of 288 (including inspectors, laboratory support, clerical and administrative support and management) means only a small percentage of what is produced and only what is exported is actually inspected by the Department. Even so, $1-2 \%$ of the lots DOF inspects are rejected, indicating that there may be potential threat to consumer health, safety and satisfaction.

The DOF along with inspection authorities and regulatory agencies in importing countries are being pressured to do more. In a period of government fiscal restraints, DOF can not by itself provide the level of inspection required. There is a need for joint action by the industry and Government to meet the challenge. Moreover, it is of utmost importance to promote the establishment of Agreement on Equivalent of the Fish Inspection System or at least Certification Agree ment with importing countries.

It was recognized that traditional inspection has certain limitations, one of which is the rapid turnover of personnel. This means that education and training must be a continuing exercise, which is rarely the case. Inspection of facilities and operation are carried out with reference to various guidelines, standards and Codes of Practices. In many case these documents fail to indicate the relative importance of various requirements and the requirements are stated in very imprecise terms such as satisfactory, adequate, suitable, if necessary etc. This leaves interpretation to the inspector who may place $b$ much emphasis on relatively unimportant factors and thus increase cost without reducing hazard. Microbiological testing also has some limitations as a control option. There are constrain of time, difficulties relating to sampling, analytical methods anduse of indicator organisms.

Since 1991, the Department of Fisheries, Thailand implemented voluntary HACCP fish inspection programs. The program has been involved with pilot HACCP implementation by the industry, reviewing inspection procedures and training for inspectors and industry. Generic HACCP plans have been developed for major commodities, through workshops and working groups with the industry. Guidelines for development of documented HACCP program or quality manual has been provided and updated to met with international guidelines and importing countries requirement on HACCP. Close monitoring of the processing industry performance in HACCP program has been carried out by inspection of facilities, control at critical control points, record review and quality program verification. Implementation by the industry is classified into three stages; initial stage, development stage and fully implemented.

In 1996, The program is mandatory for approved fish processors under jurisdiction of the Department.DOF laid down conditions to be met by the approved processors relating to HACCP quality program. Approved processors must have HACCP program implemented, documented and verified by the Department. HACCP audit procedures is developed and updated.

In 1999, other food industry such as meat, poultry, vegetables and fruit products started implementing HACCP, HACCP audits for those are performed by many government agencies and institutes such as Department of Livestock Development, Food and Dnig Administration, Thai Industrial Standard Institute and the National Food Institute.

\section{HACCP Approaches :}

The Department of Fisheries HACCP Program is focused on product safety, other quality related elements, hygiene and Good Manufacturing Practices (GMP) are to be met by prerequisite program.

HACCP program is comprehensive, it will cover productions, processing, input materials, products and personnel at critical control points. In many cases what the program demands is already being done; it can be described as a formulation of good manufacturing practices. Each processing establishment must develop a HACCP plan appropriate to their processing practice, hygiene and sanitation status. The processor must identify hazards associated with the products and processing environment. Hazard analysis and risk assessment should be conducted extensively. The processor must to have basic sanitation, hygiene control and GMPs as prerequisile program. Once the hazards are identified, critical control points can be easily determined using a 
decision-tree approach, keeping critical control points to a minimum as to control product safety. By this approach, confusion between critical control points (CCP) and control points (CP) is greatly reduced. (Suwanrangsi, S. 1996)

It is required that HACCP plan and prerequisite program be documented.

Guidelines for program development and documentation are also provided and handbook are available to industry in local language.

\section{Role of industry}

Each operation must institute a prerequisite program and a HACCP program. They must also verify by $\mathrm{HACCP}$ plan or prerequisite program that regulatory requirements are being met. For each critical control point the company must analyze hazard; establish preventive measures, monitoring procedures, critical limits, and corrective action; and also identify verification procedures. Most importantly, a system of record keeping must be established to indicate activities done, instances of non-compliance found, and corrective actions and verification taken.

\section{Role of the Department of Fisheries}

DOF established the rules for HACCP implementation to be applied by the establishment. These conditions are to be met by all DOF approved establishments. In addition, the Department issued guidelines for HACCP program development and documentation. DOF also provide training on ad hoc basis for industry. DOF will assess the HACCP programs of the processing plants in three ways:

1 by verify the design and appropriateness of the documented HACCP program to processing condition of the establishment.

1.1 The Department of Fisheries will validated the documented HACCP program (HACCP Quality Manual) of approved processors based on HACCP Program Rating Report (Department of Fisheries, 1996)

1.2 The program is considered satisfactory, when non compliance identified is corrected by the company

1.3 Processor will have a maximum of 3 months to correct non compliances and re submit the plan for reviewing

2 by conducting independent inspection of products and facilities, as is the case at present to evaluate adequacy of prerequisite program.
2.1 Inspection will be carried out using Plant Inspection Rating Report. (Department of Fisheries, 1996)

2.2 Processors shall meet a minimum of Level 4 ( no more than 2 serious non compliances and 10 major non compliances for the prerequisite program.

3. by auditing the processors' HACCP activities This third method relies heavily on inspection of CCPs activities and the plants' record. DOF will examine the record and will perform independent inspections to verify their accuracy. The result of these three types inspections taken together will determine how effectively the plant HACCP program is operating and this, in turn, will determine the frequency of the regular inspection of the plant and of the products.

3.1 Inspection will be carried out using HACCP Implementation Rating Reporl(Department of Fisheries, 1996).

3.2 The program is considered satisfactory when all non compliance identified are corrected.

3.3 Processor will have a maximum of 3 months to correct noncompliance identified.

This has been done in certain cases, under an agreement and a memorandum of understanding with foreign countries, by DOF. The amount of DOF activity or involvement in the plant and in end product inspection will vary directly with the effectiveness of the HACCP program and the processors' hygiene standard and also product compliance.

The most important activities for successful implementation of HACCP istraining on the principle and application of HACCP for the fish processing industry from 1991-1997. However, since 1998, the focus has been on HACCP audit, development of policy and procedures, procedural manual, guidelines, and criteria for assessment To meet needs of industry needs on guidance in designing, preparing of documented HACCP plan and prerequisite program, as well as implementing and maintaining the program, DOF has laid down and published

- policy and procedures on HACCP

- guidelines or handbook for HACCP documentation

- guidelines on assessment process.

- guidelines on hazards and control and allowance limits or process criteria. 
Various govermment agencies, universities and private HACCP consulting firm currently offer training on HACCP.

The role of DOF in providing guidance during inspection are to

- Clearly explain health and safety sandard, regulation guidelines or requirement used as references to their inspecion.

- Provide references that is conductive to the implementation of HACCP.

- Provide details and reasons related to assessment process, non-compliance identified i.e. related requirement, nature of problems, objective evidence, but not how to correct the noncompliance.

- Confirm the industry understanding of HACCP

- Encourage the application of all 7 principles of HACCP

- Conduct assessment according to good audit practices

HACCP audit policy and procedures are developed for the field inspectors. Training on HACCP verification or HACCP system andit are provided for the inspectors as well as harmonization meeting among regional inspectors to ensure consistency and competency. Inspectors are also trained specifically on HACCP audit and ISO 9000 Lead Assessor Training, to build up their audit skill.

In 2000, HACCP application is progressing, 201 fish processors has been approved by DOF anong these there are148 freezing plants, 35 canneries, 15 traditional product processors and $3 \mathrm{fresh} / \mathrm{chilled}$ products processors.

\section{Key Problems in HACCP Implementation}

Hazards Differ-- Each species or group of similar fish, molluscan shellfish or crustacean may have quite different hazards which also varyfrom one country or region to the next. Aquaculture has resolved those problems to some extent by creating a more controlled environment for fish breeding before harvesting. However, aquaculture species have distinct hazards of their own

Inadequate basic quality and sanitation.Over $70 \%$ of fish products traded intemationally had quality defects ranging from decomposition, contamination with pathogens or foreign bodies to discrepancies in stated weight and incorrect labeling. This failure illustrates the scale of the problems faced in effective implementation of HACCP systems.
Given the involvement of smaltscale producers in developing countries in the supply chain, there are major weaknesses in basic good manufacturing and hygiene practice. HACCP can only be effective if it is based on a solid foundation of Good Manufacturing Practices (GMP), Sanitation Standard Operating Procedures (SSOPs), and clear Standard Operating Procedures (SOPs).

Application limited to processing level only--To date the HACCP system is applied only to the processing level by the fishery industry worldwide. In developing countries they have generally only been applied to the expon oriented factory. HACCP must start at the aquaculture/harvesting stage and continue through processing, distribution and retail handling to consumer education. There have been some initiatives to address HACCP implementation within aquaculture, but these are limited.

Differing HACCP models-- HACCP systems differ greatly. The EU and the United States Food and Drug Administration (USFDA) seafood HACCP programs concentrate on food safety. Other models such as those developed by the US National Marine Fisheries Services and the Canadian Quality Management Program, for example, also include quality issues. The Australian government, for example, has developed SQF 2000, a system combining HACCP and selected elements of ISO 9000. The Codex Committee on Fish and Fishery Products is currently revising the Code of Practices for Fish and Fishery Products to incorporate HACCP principles and also essential quality issues such as composition and labeling. Its model proposes the use of Defect Action Points (DAPs) based in part on Critical Control Points (CCPs) in HACCP systems. The current range of models can be very confusing, even for experts, let alone the smaltscale processor, and puts a greater responsibility on the regulatory authorities to provide clear guidance and training.

In Developing countries, the fisheries industry is dominated by small primary processors. Resources are also a major issue, both in terms of the finance and expertise available for HACCP implementation. Guidance on HACCP systems needs to take account of these limitations, and there is a greater need for government support In practice, for many of those involved in the industry, the first priority needs to be sound prerequisite systems. Once these are functioning effectively, experience with fish processors in Thailand suggests that HACCP systems become much simpler to design and manage, both for large and small businesses. 
Lack of commitment and understanding-Securing a genuine commitment to HACCP implementation is a critical issue. Many businesses expressed an initial indifference to the concept. A common response was complacency: businesses had operated for many years without serious problems or complaints, so why the need for change? A major force for changing attitudes was commercial pressure, particularly once HACCP implementation became a prerequisite for exporting to the USA and the $\mathrm{EU}$, and an important way of boosting trade with other countries such as Canada and Australia. Where firms have not come under pressure from customers or needed to respond to the needs of particular export markets, HACCP implementation has remained extremely patchy. Only when management viewed HACCP implementation as an essential tool for the improvement of product quality and safety, and for building a stronger competitive position, was it likely to make HACCP a success.

Resource requirements-- In addition to the cost of hygiene upgrading, documentation and preparing plans, training is a major commitment businesses need to plan for and cost at the outset. Companies often underestimated the amount of training required. These commitments include:

Sanitation and hygiene training for line personnel in building effective prerequisite systems.

In-depth training for the HACCP team leader. Companies implementing HACCP systems successfully were those willing to send team leaders to accredited courses, so that they could be sure of having someone familiar with all the stages of HACCP implementation.

Training for HACCP teams, often through a one-day course on HACCP principles and the role of HACCP teams.

Audit training to equip personnel to carry out internal audits.

Training in monitoring and verification skills for CCP staff.

Meeting differing HACCP requirements and other standards-- A particular problem facing businesses exporting to a range of markets is that they face differing requirements and competing HACCP models from differing national administrations. An additional problem is a constant stream of changes and additions as differing national regulations evolve. This problem of multiple and moving standards places a particular responsibility on govemment. The Department of Fisheries works closely with the industry in defining the common minimum requirements for a HACCP system which will meet the main requirements of a company's export markets. Some companies have then developed a basic HACCP plan, which, once implemented, has then gradually developed to meet particular national statutory requirements where required. Regular review, often in consultation with the Department of Fisheries, is required to keep up with developments in differing national jurisdictions.

Language-- Language is a major challenge to the successful implementation of HACCP in non English speaking countries. Even in English, explaining HACCP concepts and procedures into terms that technicians and workers at the plant level can cope with is formidable enough. Translation into a foreign language can result in confusing the meaning of even the basic HACCP terms such as "hazard." In some cases, newly-emerged pathogens, for example, do not have any local language name and cannot be precisely translated, making it difficult to distinguish them from other pathogens and explain their nature and dangers.

Demands of translation are compounded by the fact that, to meet export customer and market requirements, HACCP plans need to be in English whereas, to be comprehensible to company staff, they need also to be written in local language. In Thailand, these problems have been resolved in part by government translation of key HACCP documentation which has then been made available to companies, often as part of initial training sessions on HACCP principles. These have provided the raw materials for developing HACCP plans in Thai language. A basic error made by a number of companies was to try to undertake some of the translation work themselves, using in-house expertise, often located within the marketing department. These attempts were usually unsuccessful, resulting in inaccurate and misleading material.

Hazard analysis-- Hazard analysis proved one of the major challenges for many businesses. Whilst many of the hazards affecting fish products are well documented, a significant number of businesses were ignorant of the full range of hazards and their potential impact on their products. They were used to reactive hazard analysis, dealing with individual hazards as they arose, particularly in response to customer concerns over final product quality. In many cases businesses lacked inhouse microbiological expertise.

The Thai Fisheries Department staff lod a key role to play in assisting businesses start the process of hazard analysis. They developed a simple hazard table, dividing hazards into biological, 
chemical or physical hazards, further subdivided by species. This framework provided a starting pant for a HACCP team. Fisheries Department staff also provided information on key information sources to consult, together with training materials on some of the main hazards, and initial advice based on experience with similar businesses.

CCPs and critical limits-- Because they confused quality and safety issues, and failed to define the scope of the HACCP study, a number of businesses produced HACCP plans which incorporated a maze of Critical Control Points (CCPs) which could not be monitored adequately and which resulted in mountain of records. Experience of HACCP plans across the fish processing sector suggested that, once prerequisite systems were operating effectively, and once quality issues were separated out, most HACCP systems were relatively simple with far fewer CCPs than many original HACCP plans.

Businesses setting up CCPs sometimes found difficulty in establishing critical limits, given different recommendations in the scientific literature or conflicting requirements from differing regulatory authorities. The validation of critical limits was another area of difficulty, especially for smallscale processors who could not nu their own challenge tests. The Department of Fisheries has been able to provide some suppon in the use of government or university research laboratories to run challenge tests. However, there remain gaps in appropriate guidance on validation procedures for critical limits, and this is an area where the Deparment itself is still developing the appropriate technicalknowledge and skills.

Documentation-- Creating and managing HACCP documentation is an obvious area where businesses face difficulties, usually from creating too much documentation of poor quality. Many of the problems are the result of confusion and poor individual document design. Experience suggests that it is important to keep documentation simple. CCP monitoring procedures should, for example, deal with a few essential issues such as:

- the purpose of the CCP

- the critical limit to be monitored

- how it is to be monitored

- the person responsible for monitoring

- where results are to be recorded

- how frequently

- what to do if the critical limit is exceeded

Audit procedures-- Since many companies have only started to implement HACCP systems at the end of the 1990s, many have not yet had the opportunity to conduct their first and full internal audit. In some cases, firms have been slow to do so because they are unfamiliar with the concept. Many tend to delay auditing because they are concentrating on day-to-day production issues and ensuring that their HACCP systems are operating smoothly. The Department of Fisheries has encouraged all businesses implementing HACCP systems to undertake an annual internal audit and, providing support as an encouragement is offered; most firms try to do so. A few firms are more resistant to internal auditing altogether.

Many businesses lack the resources to fund an external audit, and must rely on appointing an internal audit team. Because auditing is still not widespread, support from the Department of Fisheries has proved essential for many companies. The Department is able to recommend accredited courses for internal auditing. Given the pressures in dealing with day-to-day issues, it is easy for andits to slip and, therefore, particularly important to set a deadline for training auditors, planning and conducting the audit, and providing a written report.

Common issues raised by audits include:

The poor quality of prerequisite systems, particularly in hygieneand sanitation.

The inadequacy of hazard analysis.

Inappropriate selection of CCPs.

Inadequate validation of critical limits.

Poor monitoring methods and frequency of monitoring.

The ineffectiveness of monitoring procedures, and the failure to take corrective action when required.

Deficiencies in the company's own audit procedures.

Measuring success: the benefits of HACCP implementation-- HACCP systems have given Thai companies greater confidence. Many companies in Thailand have, on the foundation of their HACCP systems, expanded their value added product lines to include more ready-prepared foods, confident of their ability to manage food safety and quality of such products. The market for these products has also grown as a result of buyers' and importers' confidence that HACCP controls are in place.

Experience from auditing companies in the Thai fishing industry has also meant that government inspectors feel it less necessary to inspect firms with accredited HACCP systems as frequently as others. Companies have reported other benefits, notably that HACCP systems have given line staff much greater 
confidence, independence and understanding, reducing their reliance on managers to solve day to day production problems. Once embedded, firms have also found they could extend HACCP principles into areas of quality, identifying critical areas for quality control and building up systems for controlling them more effectively. The value of HACCP systems in fish processing can be seen in the way companies have retained them in preference to other management systems such as ISO 9002 .

Conclusions: the future of HACCP-- HACCP systems demand a business and staff at all levels willing to take more responsibility for and control of the business's operations, rather than relying on others to identify problems and improvements, whether they be customers, regulators or more senior managers. The success of HACCP implementation in the Thai fisheries industry has also been dependent on close cooperation between industry and government, and the willingness of the latter to play a proactive role in HACCP implementation.

There are a number of improvements that need to be made. These include the following:

HACCP systems are still concentrated in processing So far they have not been extended further along the supply chain, particularly in marine capture and aquaculture. Many people have still argued for the extension of HACCP principles into such areas as retail sale and consumer handling of fish products HACCP take-up amongst smaller businesses remains poor. Government needs to keep abreast of changes in HACCP regulations and standards internationally, There need to be improved practical guidelines for hazard analysis.

Inspectors need to gain more expertise and experience in effective inspection techniques, translating HACCP theory into effective practice and to exert pressure for greater standardization. As an example, inspectors need to be able to use generic HACCP models flexibly, accepting variations which are appropriate to a particular business. There needs to be more research in such areas as the validation of critical limits.

\section{Reference:}

1. Suwanrangsi, $\mathrm{S}$ HACCP Implementation: Experiences of Developing Countries US Seafood News Volume 9, Issue 3, 2001.

2. Suwanrangsi, S HACCP Implementation in the Thai Fisheries Industry. In: Mayes T, Metimore, $S$ (eds). Making the Most of HACCP. Woodhead Publishing Limited. Cambridge. 2001. 